\title{
Calcium compartments in vascular smooth muscle cells as detected by aequorin signal
}

\author{
${ }^{1}$ Fujio Abe, *Minori Mitsui, *Hideaki Karaki \& Masao Endoh
}

Department of Pharmacology, Yamagata University School of Medicine, Yamagata 990-23, and *Department of Veterinary Pharmacology, Graduate School of Agriculture and Life Sciences, The University of Tokyo, Bunkyo-ku, Tokyo 113, Japan

1 To examine whether cytosolic $\mathrm{Ca}^{2+}$ in smooth muscle cells distributes evenly, cytosolic $\mathrm{Ca}^{2+}$ levels were measured with two different $\mathrm{Ca}^{2+}$ indicators in the ferret isolated portal vein; a fluorescent indicator, fura-PE3, that shows the average $\mathrm{Ca}^{2+}$ level, and a photoprotein, aequorin, that preferentially shows a high $\mathrm{Ca}^{2+}$ compartment.

2 A noradrenaline $(10 \mu \mathrm{M})$-induced sustained contraction was associated with a sustained increase in the fura-PE3 signal, or a transient increase followed by small sustained increase in the aequorin signal. A high $\mathrm{K}^{+}$-induced contraction was associated with a sustained increase in both the fura-PE3 and aequorin signals.

3 A second application of noradrenaline or high $\mathrm{K}^{+}$induced reproducible contractions and fura-PE3 signals. In contrast, the aequorin signal resulting from a second application of noradrenaline or high $\mathrm{K}^{+}$ was much smaller than the first signal.

4 Following a $13 \mathrm{~h}$ but not a $3 \mathrm{~h}$ resting period, the aequorin signal stimulated by noradrenaline or high $\mathrm{K}^{+}$recovered, without any change in the contractile response.

5 In $\mathrm{Ca}^{2+}$-free solution, high $\mathrm{K}^{+}$was ineffective, whereas noradrenaline induced only a small aequorin signal and contraction compared to those obtained in the presence of external $\mathrm{Ca}^{2+}$. After the addition of $\mathrm{Ca}^{2+}$, the first application of noradrenaline induced a large aequorin signal and a large contraction, although a second application induced a much smaller aequorin signal accompanied by a large contraction.

6 These results suggest that high $\mathrm{K}^{+}$and noradrenaline increase $\mathrm{Ca}^{2+}$ in at least two cytosolic compartments; a compartment that is coupled to the contractile mechanism ('contractile' $\mathrm{Ca}^{2+}$ compartment; major portion of cytoplasm containing contractile elements) and a compartment that is not coupled to contractile mechanisms ('non-contractile' $\mathrm{Ca}^{2+}$ compartment; small sub-membrane area that does not contain contractile elements). On stimulation, the $\mathrm{Ca}^{2+}$ level in the 'contractile' compartment may increase to a level high enough to stimulate myosin light chain kinase but not so high as to consume aequorin rapidly. In contrast, the $\mathrm{Ca}^{2+}$ level in the 'non-contractile' compartment may increase so greatly that aequorin in this compartment is rapidly consumed. These two compartments may be separated by a diffusion barrier and, during a resting period, aequorin may slowly diffuse from the 'contractile' compartment to the 'non-contractile' compartment and thus restore the full aequorin signal. An increase in $\mathrm{Ca}^{2+}$ in the 'non-contractile' compartment seems to be dependent mainly on $\mathrm{Ca}^{2+}$ influx and partly on $\mathrm{Ca}^{2+}$ release.

Keywords: Cytosolic $\mathrm{Ca}^{2+}$ level; $\mathrm{Ca}^{2+}$ indicators; $\mathrm{Ca}^{2+}$ localization; $\mathrm{Ca}^{2+}$ signal; aequorin; fura-PE3; smooth muscle; noradrenaline; $\mathrm{Ca}^{2+}$ compartment; ferret portal vein

\section{Introduction}

$\mathrm{Ca}^{2+}$ is the primary regulator of smooth muscle contraction. Contractile stimuli increase the cytosolic $\mathrm{Ca}^{2+}$ level $\left(\left[\mathrm{Ca}^{2+}\right]_{i}\right)$ by releasing stored $\mathrm{Ca}^{2+}$ and/or by opening $\mathrm{Ca}^{2+}$ channels (Karaki \& Weiss, 1988). Measurements of $\left[\mathrm{Ca}^{2+}\right]_{i}$ simultaneously with contraction is a useful method to elucidate the mechanism of regulation of smooth muscle contraction by $\mathrm{Ca}^{2+}$. For this purpose, a photoprotein, aequorin (Blinks et al., 1978), and the fluorescent $\mathrm{Ca}^{2+}$ indicators such as fura-2 and indo-1 (Grynkiewicz et al., 1985) are widely used. However, the results obtained with these two types of $\mathrm{Ca}^{2+}$ indicators are not always consistent. It has been shown that the intensity of aequorin luminescence correlates with the 2.5 power of $\mathrm{Ca}^{2+}$ concentration (Blinks et al., 1978) whereas the fluorescence of fura- 2 analogues changes as a linear function of $\mathrm{Ca}^{2+}$ concentration (Grynkiewicz et al., 1985). Therefore, if the $\mathrm{Ca}^{2+}$ level in a small compartment of the cell becomes higher than the rest of the cell, the aequorin signal becomes higher than the fura-2 signal obtained from the same cell, and

\footnotetext{
${ }^{1}$ Author for correspondence.
}

this may be at least partly responsible for the difference in $\mathrm{Ca}^{2+}$ signals obtained with these two types of $\mathrm{Ca}^{2+}$ indicators (Karaki, 1989). This unique property of aequorin makes it suitable for detecting the existence of a high $\mathrm{Ca}^{2+}$ compartment in a cell.

Recently, it has been suggested that in smooth muscle cells there is a high $\mathrm{Ca}^{2+}$ compartment in restricted diffusion spaces between the plasma membrane and intracellular organelles (Chen \& van Breemen, 1993; Kargacin, 1994; Etter et al., 1994). Compartmentalized high $\mathrm{Ca}^{2+}$ may locally activate membrane ion channels, ion pumps, exchange carriers and enzymes without activating the contractile elements located in the central cytoplasm of the cell. It has also been suggested in cardiac cells that there is a $\mathrm{Ca}^{2+}$ compartment localized to the inner sarcolemmal leaflet anionic phospholipid that maintains a high concentration of $\mathrm{Ca}^{2+}$ for a short period of time (Langer, 1994).

To examine further the possibility of $\mathrm{Ca}^{2+}$ compartmentalization in smooth muscle cells, we compared the $\mathrm{Ca}^{2+}$ signals measured with aequorin and a fura-2 analogue, fura-PE3 (Takayama et al., 1994), in the ferret isolated portal vein.

Some of these results has been briefly reported (Karaki et al., 1994). 


\section{Methods}

Ferrets of either sex, weighing $700-1,200 \mathrm{~g}$, were killed by exsanguination under ether anaesthesia and the portal vein was isolated. To exclude the effects of endogenous adrenergic nerves, the adventitia was removed (Abe \& Endoh, 1990). The vein was cut into a helical strip, $2-3 \mathrm{~mm}$ in width and the endothelium was removed by gently rubbing the intimal surface with a cotton swab moistened with physiological salt solution that contained (in $\mathrm{mM}$ ): $\mathrm{NaCl} 116.4, \mathrm{KCl} 5.4, \mathrm{CaCl}_{2}$ 1.8, $\mathrm{MgSO}_{4}$ 1.0, $\mathrm{NaHCO}_{3} 23.8, \mathrm{NaH}_{2} \mathrm{PO}_{4} 0.9$ and glucose 5.5. High $\mathrm{K}^{+}$solution was made by substituting $\mathrm{NaCl}$ with equimolar $\mathrm{KCl}$. These solutions were saturated with $95 \% \mathrm{O}_{2}$ and $5 \% \mathrm{CO}_{2}$ mixture at $22^{\circ} \mathrm{C}$ to maintain the $\mathrm{pH}$ at 7.4

Aequorin was loaded as reported previously (Morgan \& Morgan, 1982; Takuwa \& Rasmussen, 1987; Rembold \& Murphy, 1988; Gerthoffer et al., 1989) with slight modifications. In brief, muscle strips were treated with $\mathrm{Ca}^{2+}$-free physiological salt solution with $10 \mathrm{mM}$ EGTA at $2^{\circ} \mathrm{C}$ for $15 \mathrm{~min}$ followed by an incubation medium containing $1 \mathrm{mM}$ EGTA at $2{ }^{\circ} \mathrm{C}$ for $20 \mathrm{~min}$. The latter solution was similar to that developed for organ transplantation (Beltzer \& Southard, 1988; Maurer et al., 1990) with the following composition (in $\mathrm{mM}$ ): $\mathrm{K}^{+}$lactobionate $100.0, \mathrm{MgSO}_{4} 5.0, \mathrm{~K}_{2} \mathrm{HPO}_{4} 25.0$, raffinose 30.0, adenosine 5.0, glutathione 3.0, alloprinol 1.0, EGTA 1.0 and insulin $100 \mathrm{ul}^{-1}$. Strips were then treated with a similar solution containing $0.1 \mathrm{mM}$ EGTA and $0.4 \mathrm{mg} \mathrm{ml}^{-1}$ aequorin (obtained from Dr J.R. Blinks, Washington University, Seattle, U.S.A.) for 18 to $20 \mathrm{~h}$. Strips loaded with aequorin were treated with $\mathrm{Ca}^{2+}$-free Eagle MEM medium (Nissui Pharmaceutical, Tokyo) at $2^{\circ} \mathrm{C}$ for $30 \mathrm{~min}$ followed by a gradual increase in $\mathrm{Ca}^{2+}$ concentration to $0.5 \mathrm{mM}$ and the temperature to $22^{\circ} \mathrm{C}$. Strips were then treated with Trowell T-8 medium (Dainippon Pharmaceutical, Osaka) for 15 to $19 \mathrm{~h}$ at $22^{\circ} \mathrm{C}$ before starting the experiments. Aequorin signals were measured with a photomultipler (R-268, Hamamatsu Photonics, Hamamatsu, Japan) at $22^{\circ} \mathrm{C}$. Force of contraction was recorded isometrically under a resting force of $10 \mathrm{mN}$.

The fura-PE3 signal was measured as described previously (Ozaki et al., 1987; Sato et al., 1988). Muscle strips were treated with $5 \mu \mathrm{M}$ acetoxymethyl ester of fura-PE3 (Texas Fluorescence Lab., Austin, TX, U.S.A.) for 3-5 h at $22^{\circ} \mathrm{C}$. Strips loaded with fura-PE3 were illuminated alternately $(48 \mathrm{~Hz})$ with 340 and $380 \mathrm{~nm}$ light. The light emitted from the muscle strips was collected into a photomultiplier through a $500 \mathrm{~nm}$ filter using a fluorimeter (CAF-100, Japan Spectroscopic, Tokyo, Japan). The ratio of fluorescence due to $340 \mathrm{~nm}$ stimulation and $380 \mathrm{~nm}$ stimulation was used as an indicator of $\left[\mathrm{Ca}^{2+}\right]$.

In the fura-PE3 and aequorin experiments, $10 \mu \mathrm{M}$ noradrenaline or $70 \mathrm{mM} \mathrm{KCl}$ was added repeatedly. In the aequorin experiments, $10 \mu \mathrm{M}$ noradrenaline and $70 \mathrm{mM} \mathrm{KCl}$ were added alternately. Since the first stimulation induced a larger aequorin signal than the second stimulation (see Results), noradrenaline was added first in some experiments and $\mathrm{KCl}$ was added first in others.

Results are expressed as mean \pm s.e.mean. Student's $t$ test was used for the statistical analysis of the results. $P<0.05$ was considered to be significant.

\section{Results}

Figure 1 shows the effects of repeated applications of $10 \mu \mathrm{M}$ noradrenaline on contraction and the fura-PE3 signal. Noradrenaline induced a sustained increase in the fura-PE3 signal and a sustained contraction. Repeated applications of noradrenaline induced similar contractions and similar fura-PE3 signals. Figure 1 also shows that $70 \mathrm{mM} \mathrm{KCl}$ induced a sustained increase in the fura-PE3 signal associated with contraction. Repeated applications of $\mathrm{KCl}$ induced similar changes in the fura-PE3 signal and similar contractions (data not shown). It was also evident that the contractile response to high $\mathrm{K}^{+}$was smaller and more phasic than that to noradrenaline, although the magnitude of the fura-PE3 signals in response to noradrenaline and high $\mathrm{K}^{+}$were almost identical.

Figure 2 shows the effects of $10 \mu \mathrm{M}$ noradrenaline and $70 \mathrm{mM} \mathrm{KCl}$ on contraction and the aequorin signal. The aequorin signal in response to noradrenaline was composed of an initial large, transient increase followed by a small sustained increase. In contrast, $\mathrm{KCl}$ induced a relatively sustained increase in the aequorin signal that was smaller than the transient signal but greater than the sustained signal induced by noradrenaline.

Figure 3 summarizes the effect of repeated applications of noradrenaline on contraction and the aequorin signal. Figure $3 \mathrm{a}$ indicates that the transient increase in the aequorin signal in response to a second application of noradrenaline was only

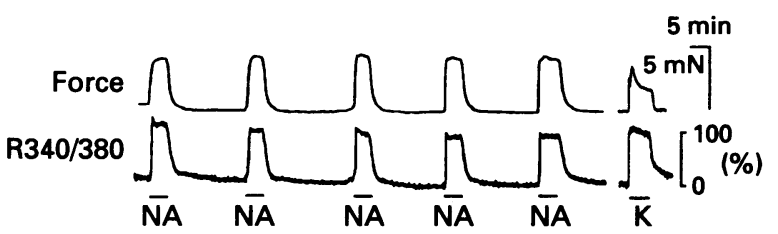

Figure 1 Effects of repeated applications of $10 \mu \mathrm{M}$ noradrenaline (NA) on the fura-PE3 signal (as indicated by R340/380) and contractile force in the ferret portal vein. $\mathrm{K}: 70 \mathrm{mM} \mathrm{KCl}$.

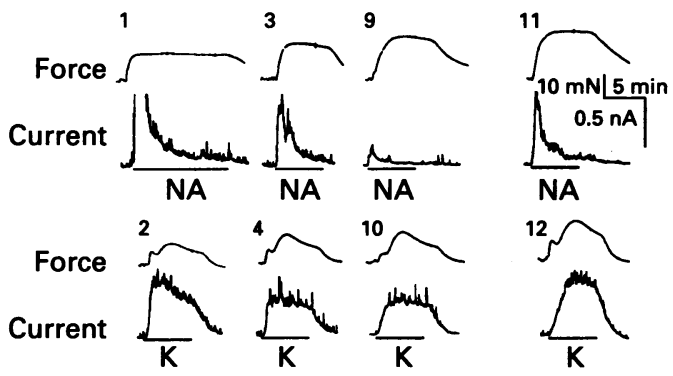

Figure 2 Effects of repeated applications of $10 \mu \mathrm{M}$ noradrenaline (NA) and $70 \mathrm{mM} \mathrm{KCl}$ on the aequorin signal (as indicated by current) and contractile force in the ferret portal vein. Noradrenaline and $\mathrm{KCl}$ were added alternately. The number indicates the sequence of stimulation. After the tenth stimulation, the muscle was left unstimulated for $13 \mathrm{~h}$ (rest) and then stimuli were applied again.

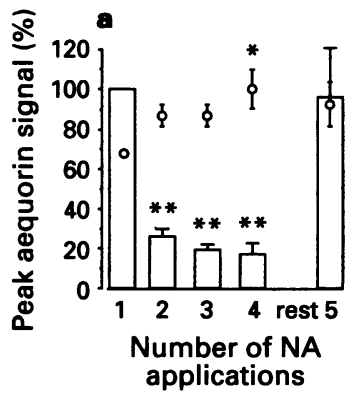

b

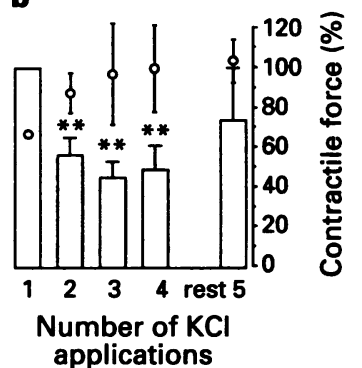

Figure 3 Effects of repeated applications of (a) $10 \mu \mathrm{M}$ noradrenaline (NA) or (b) $70 \mathrm{mM} \mathrm{KCl}$ on the peak aequorin signal (columns, left ordinate scale) and contractile force ( $\mathrm{O}$; right ordinate scale). Rest: rest for $13 \mathrm{~h}$. Mean \pm s.e. mean of 4 experiments are shown. Significantly different from the response to the first addition of stimulus: ${ }^{*} P<0.05$ and ${ }^{* *} P<0.01$. 
$26 \%$, and the third aequorin signal was $20 \%$ of the first signal. In contrast, a second application of noradrenaline induced a contraction that was slightly greater than that induced by the first application. The small sustained increase in the aequorin signal also did not change with repeated applications of noradrenaline (Figure 2). After a rest period of $13 \mathrm{~h}$, the transient aequorin signal in response to noradrenaline recovered almost completely. However, the transient aequorin signal did not recover after a resting period of only $3 \mathrm{~h}$ (data not shown).

Figure $3 \mathrm{~b}$ shows the effects of repeated applications of the high $\mathrm{K}^{+}$on contraction and the aequorin signal. The aequorin signal in response to a second application of high $\mathrm{K}^{+}$was $56 \%$ of the first signal and repeated stimulation did not induce a further decrease. Again, the contraction induced by the second application of high $\mathrm{K}^{+}$was greater than that induced by the first. After a resting period of $13 \mathrm{~h}$, the aequorin signal in response to high $\mathrm{K}^{+}$recovered almost completely.

Alternate applications of noradrenaline and high $\mathrm{K}^{+}$indicated that the first aequorin signal was always greater than the second irrespective of the first stimulant (the second signal induced by high $\mathrm{K}^{+}$was $50 \%$ of the first signal induced by noradrenaline, as shown in Figure 2, and the second aequorin signal induced by noradrenaline was $64 \%$ of the first signal induced by high $\mathrm{K}^{+}$; data not shown).

Figure 4 shows the effects of repeated application of noradrenaline in the absence and presence of external $\mathrm{Ca}^{2+}$ and Figure 5 summarizes the results. In a $\mathrm{Ca}^{2+}$-free solution containing $0.5 \mathrm{mM}$ EGTA, the first application of noradrenaline induced only a small aequorin signal in association with a small contraction. After repriming by incubation with a solution containing $\mathrm{Ca}^{2+}$, the muscle strip was incubated in $\mathrm{Ca}^{2+}$ free solution and noradrenaline was applied again. The second application of noradrenaline induced an aequorin signal that was slightly smaller (but not statistically different) than the first signal, although the contractions induced by the first and second applications of noradrenaline were almost identical. After repriming, the third and the fourth applications of noradrenaline induced smaller aequorin signals although contractions did not change. The muscle was then incubated in a solution containing $\mathrm{Ca}^{2+}$ and noradrenaline was applied again. The first aequorin signal in the presence of $\mathrm{Ca}^{2+}$ (the fifth stimulation from the beginning) was much greater than that obtained in $\mathrm{Ca}^{2+}$-free solution. However, the second (the sixth from the beginning) aequorin signal was only $24 \%$ of the previous signal. In contrast, contractions induced by repeated applications of noradrenaline in the presence of external $\mathrm{Ca}^{2+}$ were almost identical. We also confirmed that high $\mathrm{K}^{+}$was ineffective in $\mathrm{Ca}^{2+}$-free solution.

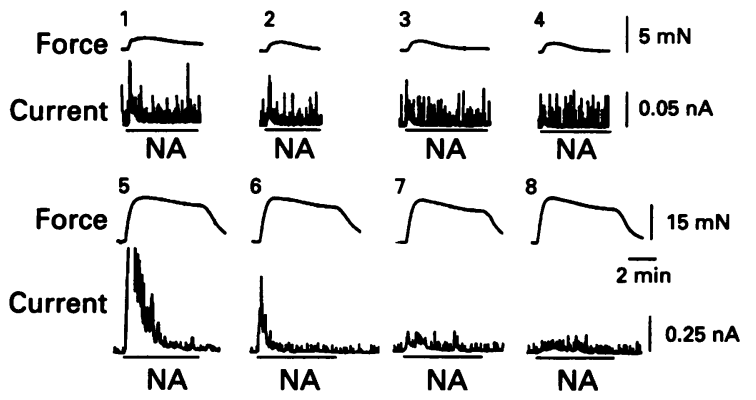

Figure 4 Effects of external $\mathrm{Ca}^{2+}$ on the aequorin signal and contractile force induced by $10 \mu \mathrm{M}$ noradrenaline (NA). The first response was obtained after a 10 min-incubation in $\mathrm{Ca}^{2+}$-free solution. The muscle was then washed with $\mathrm{Ca}^{2+}$-free solution followed by an incubation in normal solution for $40 \mathrm{~min}$ for repriming. The muscle was washed with $\mathrm{Ca}^{2+}$-free solution for $10 \mathrm{~min}$ and noradrenaline was applied again (Karaki et al., 1979). This sequence was repeated four times ( 1 to 4$)$. The muscle was then incubated in normal solution and noradrenaline was repeatedly applied (5 to 8). Note that scales for upper $\left(\mathrm{Ca}^{2+}\right.$-free solution) and lower figures (in the presence of $\mathrm{Ca}^{2+}$ ) are different.

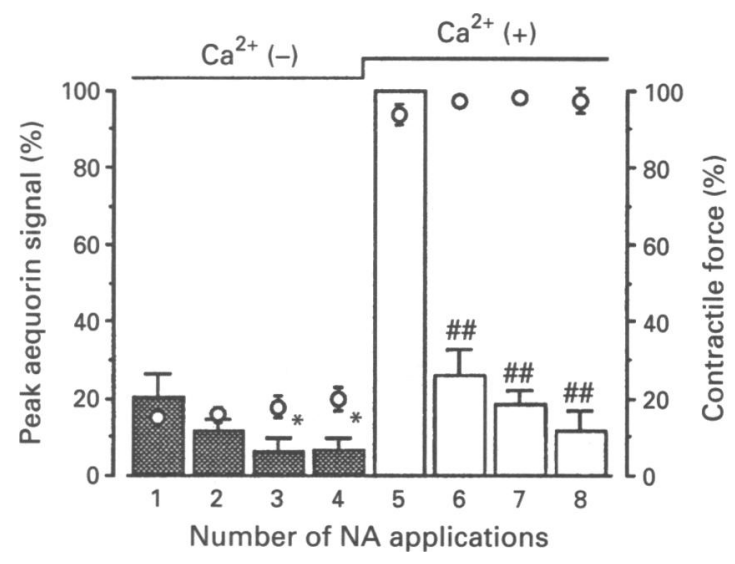

Figure 5 Effects of external $\mathrm{Ca}^{2+}$ on the peak aequorin signal (columns, left ordinate scale) and contractile force ( $O$; right ordinate scale) induced by $10 \mu \mathrm{M}$ noradrenaline (NA). The experiment was performed as shown in Figure 4. The mean and s.e. mean of 6 experiments are shown. Significantly different from the response to the first addition of stimulus: ${ }^{*} P<0.05$. Significantly different from the response to the fifth addition of stimulus: $\# P<0.01$.

\section{Discussion}

In the present experiments, it was found that stimulation with noradrenaline or high $\mathrm{K}^{+}$increased $\mathrm{Ca}^{2+}$ signals measured with fura-PE3 or aequorin. However, there were differences between the fura-PE3 and aequorin signals. Although noradrenaline induced a sustained increase in the fura-PE-3 signals, it induced a transient increase followed by small sustained increase in the aequorin signal. In addition, the first and the second applications of noradrenaline induced almost similar increases in the fura-PE3 signal whereas a second application of noradrenaline induced a much smaller aequorin signal than that induced by the first. The decrease in the aequorin signal was due to a decrease in the transient phase but not the sustained phase.

The contraction, fura-PE3 signal and sustained phase of the aequorin signal did not decline with repeated stimulation. Thus, the decrease in the transient phase of the aequorin signal does not reflect reduced activation. One possible explanation is that the signal declines because the active aequorin declines. Aequorin is consumed by binding to $\mathrm{Ca}^{2+}$ (Blinks et al., 1978). Thus, it is suggested that noradrenaline induced a large increase in $\mathrm{Ca}^{2+}$ in a small cytosolic compartment; aequorin in this compartment was probably rapidly consumed during the first application of noradrenaline, and an increase in $\mathrm{Ca}^{2+}$ in this compartment induced by a second application of noradrenaline would not be detectable by aequorin. Because consumed aequorin cannot be regenerated in the cell in our in vitro system (Shimomura \& Johnson, 1975), recovery of the aequorin signal may have resulted from diffusion of aequorin from the surrounding area to this compartment. It took much longer than $3 \mathrm{~h}$ for complete recovery of the aequorin signal, suggesting that this compartment is isolated from the surrounding area by a diffusion barrier. Such a diffusion barrier may also help to keep a high $\mathrm{Ca}^{2+}$ concentration in this compartment. In swine carotid artery, Rembold \& Murphy (1988) reported that histamine induced an initial large increase in the aequorin signal that was not observed when it was added again after a 15 min resting period, suggesting that focal aequorin consumption had occurred. In their experiments, the aequorin signal recovered fully after a $2.5 \mathrm{~h}$ rest period and thus is much shorter than that required in our experiments. This difference may be due to the difference in the experimental temperature used by them $\left(37^{\circ} \mathrm{C}\right)$ and us $\left(22^{\circ} \mathrm{C}\right)$ or to tissue differences.

The present results also suggested that the noradrenalineinduced transient increase in the aequorin signal represents a $\mathrm{Ca}^{2+}$ compartment that is not directly coupled to smooth 
muscle contraction ('non-contractile' $\mathrm{Ca}^{2+}$ compartment). The 'non-contractile' $\mathrm{Ca}^{2+}$ compartment may be identical to the sub-membrane restricted $\mathrm{Ca}^{2+}$ compartment (see Introduction). The transient aequorin signal may be due to a large increase in $\mathrm{Ca}^{2+}$ in a small 'non-contractile' compartment. In contrast, the sustained increase in the aequorin signal and a large proportion of fura-PE3 signal may represent the 'contractile' $\mathbf{C a}^{2+}$ compartment, as suggested previously (Karaki, 1989). Using a membrane-associated $\mathrm{Ca}^{2+}$ indicator, Etter et al. (1994) showed that repeated stimulation of smooth muscle cells induced consistent increases in $\mathrm{Ca}^{2+}$ in the near-membrane area, suggesting that the 'non-contractile' $\mathrm{Ca}^{2+}$ does not decline on repeated stimulation.

Although high $\mathrm{K}^{+}$induced a relatively sustained increase in aequorin signal, the signal in response to the second application of high $\mathrm{K}^{+}$was smaller than that induced by the first application. It was also observed that the aequorin signal recovered after a long resting period. These results suggest that high $\mathrm{K}^{+}$also increases $\mathrm{Ca}^{2+}$ in both the 'contractile' and 'noncontractile' compartments. Since noradrenaline and high $\mathrm{K}^{+}$ showed a cross-tachyphylactic effect on the aequorin signal, these two stimulants may share the ability to increase $\mathrm{Ca}^{2+}$ in the same 'non-contractile' compartment.

Since noradrenaline has been shown to release $\mathrm{Ca}^{2+}$ from the sarcoplasmic reticulum (Karaki \& Weiss, 1988), we examined whether the transient aequorin signal (representing an increase in 'non-contractile' $\mathrm{Ca}^{2+}$ ) is due to $\mathrm{Ca}^{2+}$ release. For this purpose, we examined the effect of noradrenaline in $\mathrm{Ca}^{2+}$. free solution. The results indicated that noradrenaline induced a transient increase in the aequorin signal that was much smaller than that obtained in the presence of external $\mathrm{Ca}^{2+}$. This change was followed by a small transient contraction. A second application of noradenaline induced a slightly (but not statistically significant) smaller aequorin signal, although a third application induced a smaller transient signal than the first. In contrast, second and third applications of noradrenaline induced almost similar contractions to those induced by a first stimulation. These results suggest that noradrenaline releases $\mathrm{Ca}^{2+}$ from storage sites and supplies $\mathrm{Ca}^{2+}$ to the 'contractile' compartment. $\mathrm{Ca}^{2+}$ may also be supplied to the 'non-contractile' compartment although its concentration may not be high enough to consume aequorin rapidly.

After the addition of $\mathrm{Ca}^{2+}$ to the medium, application of noradrenaline induced a large transient increase in the aequorin signal although a second application induced only a small increase. These results suggest that the noradrenalineinduced transient increase in the aequorin signal is mainly due to $\mathrm{Ca}^{2+}$ influx and only partly due to $\mathrm{Ca}^{2+}$ release. In contrast, the response to high $\mathrm{K}^{+}$was abolished in the absence of external $\mathrm{Ca}^{2+}$. Since not only high $\mathrm{K}^{+}$but also noradrenaline open the voltage-dependent $\mathrm{Ca}^{2+}$ channel in vascular smooth

\section{References}

ABE, F. \& ENDOH, M. (1990). Role of neuronal components in the high $\mathrm{K}$-induced changes in calcium transient in the aequorinloaded ferret portal vein. Jpn. J. Pharmacol., 52 (suppl. 1) 343P.

BELTZER, F.O. \& SOUTHARD, J.H. (1988). Principles of solid-organ preservation by cold storage. Transplant, 45, 673-676.

BLINKS, J.R., MATTINGLY, P.H., JEWELL, B.R., VAN LEEUWEN, M., HARRER, G.C. \& ALLEN, D.G. (1978). Practical aspects of the use of aequorin as calcium indicator: assay, preparation, microinjection, and interpretation of signals. In Methods in Enzymology, vol. 57, pp. 292-328. New York: Academic Press.

CHEN, Q. \& VAN BREEMEN, C. (1993). The superificial buffer barrier in venous smooth muscle: sarcoplasmic reticulum refilling and unloading. Br. J. Pharmacol., 109, 336-343.

ETTER, E.F., KUHN, M.A. \& FAY, S.F. (1994). Detection of changes in near-membrane $\mathrm{Ca}^{2+}$ concentration using a novel membraneassociated $\mathrm{Ca}^{2+}$ indicator. J. Biol. Chem., 269, 10141-10149.

GERTHOFFER, W.T., MURPHY, K.A. \& GUNST, S.J. (1989). Aequorin luminescence, myosin phosphorylation and active stress in tracheal smooth muscle. Am. J. Physiol., 257, C1062-C1068. muscle cells (Sato et al., 1988; Karaki et al., 1991), an increase in $\mathrm{Ca}^{2+}$ in the 'non-contractile' compartment may be due to $\mathrm{Ca}^{2+}$ influx through voltage-dependent $\mathrm{Ca}^{2+}$ channels. Noradrenaline-induced $\mathrm{Ca}^{2+}$ release and activation of verapamilinsensitive $\mathrm{Ca}^{2+}$ entry (Karaki et al., 1991) may also supply $\mathrm{Ca}^{2+}$ not only to the 'contractile' compartment but also to the 'non-contractile' compartment.

In the present experiments, the fura-PE3 signal seemed to be a better reporter of 'contractile' $\mathrm{Ca}^{2+}$ than the aequorin signal. However, noradrenaline induced a greater contraction than high $\mathrm{K}^{+}$although the magnitude of their respective fura-PE3 signals were almost identical. It has also been shown that ileal contraction mediated by nerve stimulation is greater than that induced by direct stimulation at a given fura-2 signal (Ito et al., 1988). This type of dissociation may be due to the $\mathrm{Ca}^{2+}$ sensitizing effect of neurotransmitters (Karaki, 1989). Furthermore, it has been shown that the initial transient increase in the fura-2 signal is not always coupled to contraction (Sakata $e t$ al., 1989; Kitajima et al., 1993). This type of dissociation may be due to the 'non-contractile' $\mathrm{Ca}^{2+}$ compartment.

From these results, it is concluded that a high $\mathrm{Ca}^{2+}$ 'noncontractile' compartment is detected by aequorin during stimulation with noradrenaline and high $\mathrm{K}^{+}$in the smooth msucle cells of the ferret portal vein. This compartment may be located near the plasma membrane (see Introduction), separated from other cytoplasmic regions by a diffusion barrier, and $\mathrm{Ca}^{2+}$ in this compartment may not be able to activate contractile elements. Noradrenaline may increase the $\mathrm{Ca}^{2+}$ level in this restricted compartment mainly by $\mathrm{Ca}^{2+}$ influx and partly by $\mathrm{Ca}^{2+}$ release, whereas high $\mathrm{K}^{+}$increases $\mathrm{Ca}^{2+}$ by increasing $\mathrm{Ca}^{2+}$ influx. The $\mathrm{Ca}^{2+}$ level in this compartment becomes so high that a large proportion of aequorin in this compartment is rapidly consumed during stimulation, leading to an attenuated aequorin signal in response to successive stimulations. Since the diffusion barrier is tight, it takes a long period of time for the $21-\mathrm{kDa}$ protein, aequorin, to diffuse into this compartment from the adjacent 'contractile' $\mathrm{Ca}^{2+}$ compartment. Both noradrenaline and high $\mathrm{K}^{+}$induce a sustained increase in $\mathrm{Ca}^{2+}$ in the cytoplasmic 'contractile' $\mathrm{Ca}^{2+}$ compartment that is directly coupled to contraction. Because the $\mathrm{Ca}^{2+}$ level in this compartment is much lower than that in the restricted high $\mathrm{Ca}^{2+}$ 'non-contractile' compartment, consumption of aequorin in the 'contractile' compartment is low.

This work was supported by Grant-in-Aid for Scientific Research from the Ministry of Education, Science and Culture, Japan.

GRYNKIEWICZ, G., POENIE, M. \& TSIEN, R.Y. (1985). A new generation of $\mathrm{Ca}^{2+}$ indicators with greatly improved fluorescent properties. J. Biol. Chem., 260, 3444-3450.

ITO, Y., KURIYAMA, H. \& PARKER, I. (1988). Calcium transients evoked by electrical stimulation of smooth muscle from guineapig ileum recorded by the use of fura-2. J. Physiol., 407, 117-134.

KARAKI, H. (1989). $\mathrm{Ca}^{2+}$ localization and sensitivity in vascular smooth muscle. Trends Pharmacol. Sci., 10, 320-325.

KARAKI, H., KUBOTA, H. \& URAKAWA, N. (1979). Mobilization of stored calcium for phasic contraction by norepinephrine in rabbit aorta. Eur. J. Pharmacol., 56, 237-245.

KARAKI, H., OZAKI, H., HORI, M., KITAJIMA, S., HARADA, K., ABE, F. \& ENDOH, M. (1994). Calcium localization in smooth muscle. J. Vasc. Res., 31, 299.

KARAKI, H., SATO, K. \& OZAKI, H. (1991). Different effects of verapamil on cytosolic $\mathrm{Ca}^{2+}$ and contraction in norepinephrinestimulated vascular smooth muscle. Jpn. J. Pharmacol., 55, 3542. 
KARAKI, H. \& WEISS, G.B. (1988). Calcium release in smooth muscle. Life Sci., 42, 111-122.

KARGACIN, G. (1994). Calcium signaling in restricted diffusion space. Biophys. J., 67, 262-272.

KITAJIMA, S., OZAKI, H. \& KARAKI, H. (1993). The effects of ATP and $\alpha \beta$-methylene-ATP on cytosolic $\mathrm{Ca}^{2+}$ and force in isolated rat aorta. Br. J. Pharmacol., 110, 263-268.

LANGER, G.A. (1994). Myocardial calcium compartmentation. Trends Cardiovasc. Med., 4, 103-109.

MAURER, E.J., SWANSON, D.K \& DEBOER, L.W.V. (1990). Comparison of UW and Collins solution for preservation of the rat heart. Transplant. Proc., 22, 548-550.

MORGAN, J.P. \& MORGAN, K.G. (1982). Vascular smooth muscle, the first recorded $\mathrm{Ca}^{2+}$ transients. Pflüger's Arch., 395, 75-77.

MORGAN, J.P. \& MORGAN, K.G. (1984). Stimulus-specific patterns of intracellular calcium levels in smooth muscle of ferret portal vein. J. Physiol., 351, 155-167.

OZAKI, H., SATO, K., SATOH, T. \& KARAKI, H. (1987). Simultaneous recordings of calcium signals and mechanical activity using fluorescent dye fura 2 in isolated strips of vascular smooth muscle. Jpn. J. Pharmacol., 45, 429-433.
REMBOLD, C.M. \& MURPHY, R.A. (1988). Myoplasmic $\left[\mathrm{Ca}^{2+}\right]$ determines myosin phosphorylation in agonist-stimulated swine arterial smooth muscle. Circ. Res., 63, 593-603.

SAKATA, K., OZAKI, H., KWON, S.-C. \& KARAKI, H. (1989). Effects of endothelin on the mechanical activity and cytosolic calcium levels of various types of smooth muscle. Br. J. Pharmacol., 98, 483-492.

SATO, K., OZAKI, H. \& KARAKI, H. (1988). Changes in cytosolic calcium level in vascular smooth muscle strips measured simultaneously with contraction using fluorescent calcium indicator fura 2. J. Pharmacol. Exp. Ther., 246, 294-300.

SHIMOMURA, O. \& JOHNSON, F.H. (1975). Regeneration of the photoprotein aequorin. Nature, 256, 236-238.

TAKAYAMA, M., TAKIZAWA, S., OZAKI, H. \& KARAKI, H. (1994). Effects of wortmannin on cytosolic $\mathrm{Ca}^{2+}$ level and force in vascular smooth muscle. Jpn. J. Pharmacol., 64 (suppl. 1), 216P.

TAKUWA, Y. \& RASMUSSEN, H. (1987). Measurement of cytoplasmic free $\mathrm{Ca}^{2+}$ concentration in rabbit aorta using the photoprotein, aequorin: effect of atrial natriuretic peptide on agonistinduced $\mathrm{Ca}^{2+}$ signal generation. J. Clin. Invest., 80, 248-257.

(Received April 18, 1995 Revised August 7, 1995 Accepted August 9, 1995) 